Copyright (C) 2012 IEEE. Personal use of this material is permitted. Permission from IEEE must be obtained for all other uses, in any current or future media, including reprinting/republishing this material for advertising or promotional purposes, creating new collective works, for resale or redistribution to servers or lists, or reuse of any copyrighted component of this work in other works. 


\title{
Voltage Analysis for Placement of DG in Multiphase Distribution Networks
}

\author{
Parachai Juanuwattanakul, Student Member, IEEE, Mohammad A.S. Masoum, Senior Member, IEEE, \\ Chittachai Niyomsak, Student Member, IEEE, and Mansour Mohseni, Member, IEEE
}

\begin{abstract}
This paper presents an effective method for placement of DG units in multiphase distribution networks based on system voltage profile. The approach consists of utilizing the positive sequence voltage ratio $V_{\text {collapse }} / V_{\text {no-load }}$ to identify the weakest three-phase bus for the installation of DG units. DG ratings are determined by evaluating their impacts on voltage profile, grid losses and maximum loading factor while considering the voltage limits at all buses. Detailed simulations are performed for the placement and sizing of a doubly fed induction generator (DIFG) in the IEEE multiphase 34 node test feeder using DIgSILENT PowerFactory software. The impacts of DIFG on voltage profile, active power loss and voltage stability margin are highlighted. Finally, simulation results indicate that voltage limits should be considered as a constraint for the methods of DG placement.
\end{abstract}

Index Terms-- Multiphase network, weakest bus, DG, DIFG, voltage profile, grid loss, and maximum loading factor.

\section{INTRODUCTION}

The present integration of Distributed Generation (DG) units in power systems has many advantages, but also challenges the performance of the old networks. One of these challenges is to investigate the location and the penetration level of DG units which can easily be absorbed in the system without major structural changes while keeping all bus voltage levels within permissible limits. Due to the high penetration of DG, voltage instability problems have become important issues in power systems. Most studies confirm that 10-15\% penetration of DG can be absorbed in the electricity network [1]. It is well-known that high penetration levels of DG may have significant impacts on voltage profile, grid loss, and voltage stability margin. These impacts may appear either positively or negatively, depending on the type of distribution networks, nature of distributed generations and load characteristics.

It seems reasonable to expect that the connection of DG to the utility grid might improve the voltage profile and will enhance the voltage stability of a distribution system while reducing active and reactive losses [2]. Even though DG has a variety of benefits, it also imposes some problems and limitations.

These problems become highly significant as the penetration level of DG increases and its impact will become

Parachai Juanuwattanakul, M.A.S. Masoum, Chittachai Niyomsak, and Mansour Mohseni are with the Department of Electrical and Computer Engineering, Curtin University, Perth, WA, Australia. (e-mail: parachai3@hotmail.com; m.masoum@curtin.edu.au; c.niyomsak@postgrad.curtin.edu.au; mansour.mohseni@curtin.edu.au). worse. This will eventually require static voltage stability analysis (based on the power flow calculation) to ensure a proper and reliable operation of the power system with large amounts of DG [3]. When the power system becomes stressed (e.g., as a result of load increasing), voltage instability can easily occur. This type of voltage instability mostly occurs at the weakest bus [4]. Therefore, both the location and the penetration level of DG become a challenging task for system planning and operation. Several methods to place DG units have been proposed including voltage sensitivity analysis [5], continuation power flow for determination of the most sensitive bus to voltage collapse [7], voltage stability index [8], optimization approaches [8-9], voltage profile and loss calculations [6, 11]. References [9-10] show that the sizing and location of DG can significantly influence the voltage profile and should be well planned to maintain the node voltages within permissible limits.

Detailed analyses of unbalanced/multiphase networks based on continuation three-phase power flow show that the three PV curves on each phase for the unbalanced networks are different [12-13]. Therefore, to determine the voltage stability margins, the method of symmetrical components has been applied to merge the three PV curves to one PV curve based on positive sequence voltage. In addition, to extend and generalize the conventional definition of bus voltage ranking index for multiphase networks, symmetrical components are also applied to the three-phase voltages resulting from threephase power flow [14].

This paper expands the well-known voltage index $\mathrm{V} / \mathrm{V}_{0}$ for balanced three-phase systems and defines an improved positive sequence voltage index of $\mathrm{V}_{\text {collapse }} / \mathrm{V}_{\text {no-load }}$ to identify the weakest buses in multiphase distribution networks. Simulation results are carried out for the IEEE multiphase 34 node test feeder to determine the appropriate location and penetration level of DG in improving voltage profile, reducing grid losses and increasing the maximum loading factor while keeping all bus voltage levels within the permissible limits. Section II discusses the bus ranking for DG placement. Section III shows the impact of DG placement. Section IV presents the test system. Simulation results and analysis are provided in Section V, followed by conclusion.

\section{Bus RANKing OF Multiphase Distribution Networks}

The approach taken in this study is utilizing the bus voltage ranking index to identify the weakest buses in multiphase distribution networks. This section starts with the definition and derivation of the conventional voltage ranking index (VRI) $\mathrm{V} / \mathrm{V}_{\mathrm{o}}$ using the two bus balanced network of Fig. 1 and 
continues to extend its application to multiphase networks using symmetrical components [14].

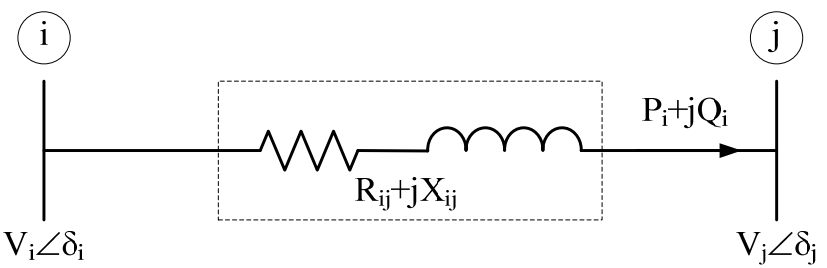

Fig. 1. Equivalent circuit of a two bus balanced network.

The conventional VRI is defined for balanced three-phase networks $[8,9]$ :

$$
V R I_{j}^{\text {conventional }}=\frac{V}{V_{0}}=\frac{V_{j, \text { base-load }}}{V_{j, \text { no-load }}}
$$

where $j$ is the bus number, $V_{j, \text { base-load }}$ and $V_{j, \text { no-load }}$ are the bus voltages for the base-load and no-load operating conditions, respectively.

Balanced three-phase load flow can be used to compute $V_{j, \text { base-load }}$ by setting the complex power at bus $j$ to zero:

$$
S_{j}=f(\delta, V)=P_{j}-j Q_{j}=\left(V_{j} \angle \delta_{j}\right)^{*}\left(\frac{V_{i} \angle \delta_{i}-V_{j} \angle \delta_{j}}{R_{i j}+j X_{i j}}\right)=0
$$

where $V_{i} \angle \delta_{i}$ and $V_{j} \angle \delta_{j}$ are the voltages at buses $i$ and $j$, respectively. Separating real and imaginary parts of (2):

$$
\begin{aligned}
& \left\{\begin{array}{l}
\operatorname{Rel}\left\{S_{j}\right\}=0 \\
\operatorname{Imag}\left\{S_{j}\right\}=0
\end{array} \Rightarrow\right. \\
& \left\{\begin{array}{l}
W_{\text {real }}\left(\delta_{i j}, V_{j}\right)=\left[P_{j} R_{i j}+Q_{j} X_{i j}\right]=V_{i} V_{j} \cos \delta_{i j}-\left(V_{j}\right)^{2} \\
W_{\text {imag }}\left(\delta_{i j}, V_{j}\right)=\left[P_{j} X_{i j}-Q_{j} R_{i j}\right]=V_{i} V_{j} \sin \delta_{i j}
\end{array}\right.
\end{aligned}
$$

where $\delta_{i j}=\delta_{i}-\delta_{j}$. The voltage $V_{j}$ is computed by squaring and adding the real and imaginary parts of (3):

$$
\begin{aligned}
& V_{j}^{4}+2\left(P_{j} R_{i j}+Q_{j} X_{i j}-0.5 V_{i}^{2}\right) V_{j}^{2} \\
& +\left(P_{j}{ }^{2}+Q_{j}{ }^{2}\right)\left(R_{i j}{ }^{2}+X_{i j}{ }^{2}\right)=0
\end{aligned}
$$

There are four solutions to (4),

$$
V_{j}= \pm \sqrt{\frac{1}{2}\left[-b \pm \sqrt{\left(b^{2}-4 c\right)}\right]}
$$

where $b=-\left(V_{i}^{2}-2 P_{j} R_{i j}-2 Q_{j} X_{i j}\right)$ and $c=\left(P_{j}^{2}+Q_{j}{ }^{2}\right)$ $\left(R_{i j}{ }^{2}+X_{i j}{ }^{2}\right)$. However, $(-b)$ is always positive because the term $\left(-2 P_{j} R_{i j}-2 Q_{j} X_{i j}\right)$ is small as compared to $\left(V_{i}{ }^{2}\right)$ and also (4c) is small as compared to $\left(b^{2}\right)$; therefore, the unique positive and stable solution of (5) is

$$
V_{j}=V_{j, \text { based-load }}=+\sqrt{\frac{1}{2}\left[-b+\sqrt{\left(b^{2}-4 c\right)}\right]}
$$

Substituting (6) in (1) results in

$$
V R I_{j}^{\text {conventional }}=\frac{V}{V_{0}}=\frac{\sqrt{\left(0.5 V_{i}^{2}-P_{j} R_{i j}-Q_{j} X_{i j}\right)+A}}{V_{i}}
$$

where $\mathrm{A}=\sqrt{0.25\left(V_{i}{ }^{2}-2 P_{j} R_{i j}-2 Q_{j} X_{i j}\right)^{2}-\left(P_{j}{ }^{2}+{Q_{j}}^{2}\right)\left(R_{i j}{ }^{2}+X_{i j}{ }^{2}\right)}$ The propose index in balanced network is defined as:

$$
V R I_{j}^{\text {balanced }}=\frac{V_{j, \text { collapse }}}{V_{j, \text { no-load }}}
$$

To compute the proposed VRI for balanced three-phase networks, $V_{j, \text { collapse }}$ is computed based on the NewtonRaphson load flow by forcing (3) to zero.

The Jacobian corresponding to (3) is defined as follows:

$$
\boldsymbol{J}=\left[\begin{array}{cc}
-V_{i} V_{j} \sin \delta_{i j} & V_{i} V_{j} \cos \delta_{i j}-2 V_{j} \\
V_{i} V_{j} \cos \delta_{i j} & V_{i} \sin \delta_{i j}
\end{array}\right]
$$

At the collapse point, Jacobian matrix is singular, therefore:

$$
\operatorname{det}(\boldsymbol{J})=0 \Rightarrow \frac{V_{j} \cos \delta_{i j}}{V_{i}}=\frac{1}{2} \Rightarrow V_{j, \text { collapse }}=\frac{0.5 V_{i}}{\cos \delta_{i j}}
$$

Substituting (6) and (10) in (8) results in

$$
V R I_{j}^{\text {balanced }}=\frac{V_{j, \text { collapse }}}{V_{j, \text { no-load }}}=\frac{0.5}{\cos \delta_{i j}}
$$

The angle is computed from (12):

$$
\delta_{i j}=\tan ^{-1}\left(\frac{\left[P_{j} X_{i j}-Q_{j} R_{i j}\right]}{\left[P_{j} R_{i j}+Q_{j} X_{i j}\right]+\left(V_{j}\right)^{2}}\right)
$$

To extend and generalize the conventional definition of VRI for multiphase networks, symmetrical components are applied to the three-phase voltages resulting from three-phase power flow. The new index is defined as the ratio of the positive sequence voltage at the collapse point to the positive sequence voltage at the no-load:

$$
V R I_{j}^{\text {unbalanced }}=\frac{V_{j, \text { collapse }}^{+}}{V_{j, \text { no-load }}^{+}}
$$

Equation (13) can be used to identify the weakest buses of both balanced and unbalanced networks. The node with the lowest bus voltage ranking index value is classified as the weakest bus.

\section{ImPACtS OF DG Placement on Voltage Profile, GRID LOSS, AND MAXIMUM LOADING FACTOR}

\section{A. Impact of DG on Voltage Profiles}

In balanced three-phase networks, voltage profiles are usually plotted using the average bus voltage values. For unbalanced networks, system unbalanced voltage variance index [15] has been proposed for considering voltage profiles instead of using system average voltage [16-17]. However, for multiphase networks, voltage magnitudes in some phases are missing. Therefore, in this paper, the voltage profiles of all phases will be plotted in the range of 0.95-1.05 p.u. (see Figs. 5 and 6).

\section{B. Impact of DG on Grid Losses}

Grid losses associated with the placement and the penetration level of a DG unit (e.g., at the weakest bus) are computed and compared with the losses without any compensation device. Active power loss reduction (ALR) by DG units or compensation devices is calculated from: 


$$
A L R=\frac{P_{\text {loss }}-P_{\text {loss }}^{D G}}{P_{\text {loss }}} \times 100 \%
$$

Where $P_{\text {loss }}^{D G}$ and $\mathrm{P}_{\text {loss }}$ are the total active power losses with and without DG units, respectively.

The DG penetration level is defined as

$$
\text { Penetration Level }=\frac{P_{D G}}{P_{\text {load }}} \times 100 \%
$$

where $P_{D G}$ and $P_{\text {load }}$ are the total active powers of the DG units and system loads, respectively.

\section{Impact of DG on Maximum Loading Factor}

Using a continuation three-phase power flow, PV curves for multiphase distribution networks will be plotted. The method of symmetrical components will then be applied to merge the three individual PV curves into a single PV curve based on positive sequence voltage. Finally, the maximum loading factor (MLF) will be determined using the single PV curve based on positive sequence voltage. MLF is defined as the ratio of the maximum system load (at the voltage collapse point) to the base load.

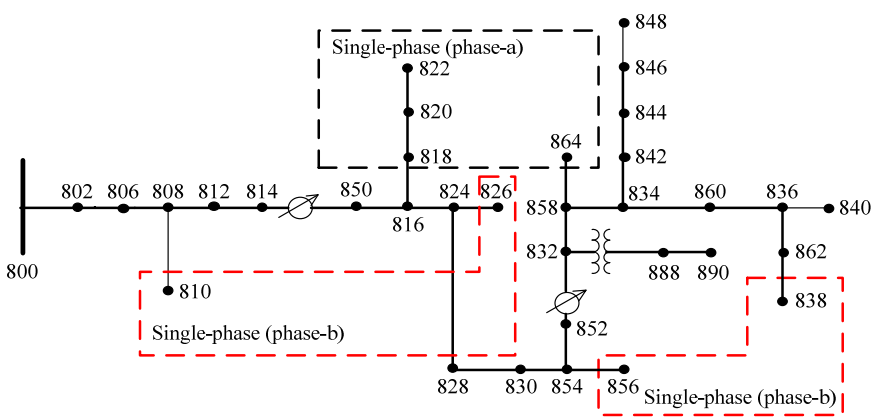

Fig. 2. The IEEE multiphase 34 node test feeder [14].

\section{Simulation Results}

For the analysis of this paper, the IEEE multiphase 34 node test feeder of Fig. 2 [18] is considered. The network has been simulated using DIgSILENT PowerFactory software [19]. The system data is available in [18]. This unbalanced multiphase feeder consists of three-phase and single-phase sections with unbalanced spot loads (Y-PQ, D-PQ, Y-I, D-I, Y-Z, and D-Z), distributed loads (Y-PQ, Y-I, Y-Z, D-I, D-Z, and D-PQ), three-phase shunt capacitors (at buses 844 and 848), and an inline transformer (between buses 632 and 688). There are also two automatic voltage regulators.

Bus 800 is treated as a slack bus with a voltage setpoint at 1.05 p.u. At a base-case load condition, the voltage at bus 890 is lower than the permeable voltage limits because the line between buses 888 and 890 is relatively long. Other bus voltages are in the permeable range of $0.95-1.05$ p.u.

\section{A. Bus Voltage Ranking Based on the Proposed Index}

Figure 3 shows the bus voltage ranking for the base-caseload with two automatic voltage regulators which regulate the voltage in the range of 0.95-1.05 p.u. According to this figure, the four lowest VRI values are buses 890, 852, 864, and 822, respectively. The weakest bus is still at bus 890.Therefore, the three-phase weakest bus is bus 890 and this bus will be selected for the installation of DG units.

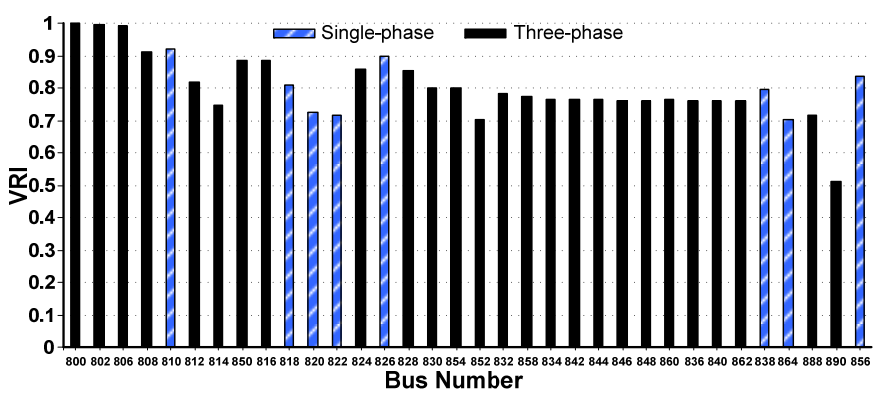

Fig. 3. Bus ranking for base-case load.

\section{B. Impacts of DG Units on Voltage Profile, Grid Loss, and Maximum Loading Factor}

A DFIG wind turbine with power factor control is installed at the weakest three-phase bus (bus 890) and its size is changed to determine its impacts on loading factor, active power loss reduction, and voltage profile.

Simulations results are presented in Fig. 4 indicating that active power loss is lowest (ALR $=62.31 \%$ ) at a DG penetration level $40 \%$ while the loading factor escalates as the DG penetration increases.

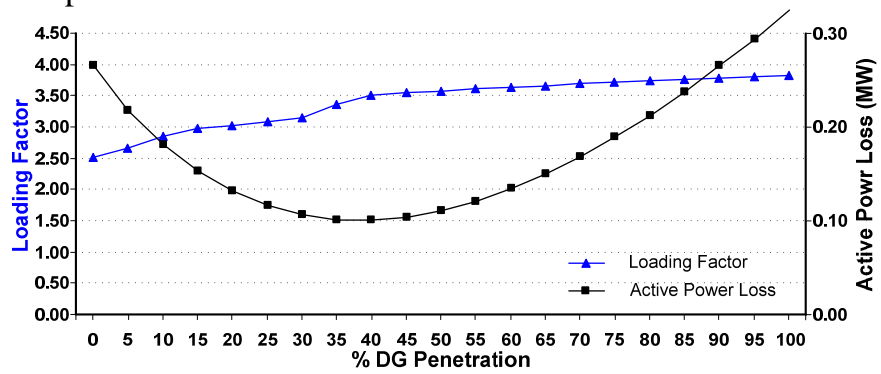

Fig. 4. Loading factor and active power loss with different DG penetration at bus 890 .

However, with $40 \%$ DG penetration at bus 890, as identify by grid loss calculation, the voltage profile of all phases at bus 890 is higher than the upper voltage limit of 1.05 p.u as shown in Fig.5.

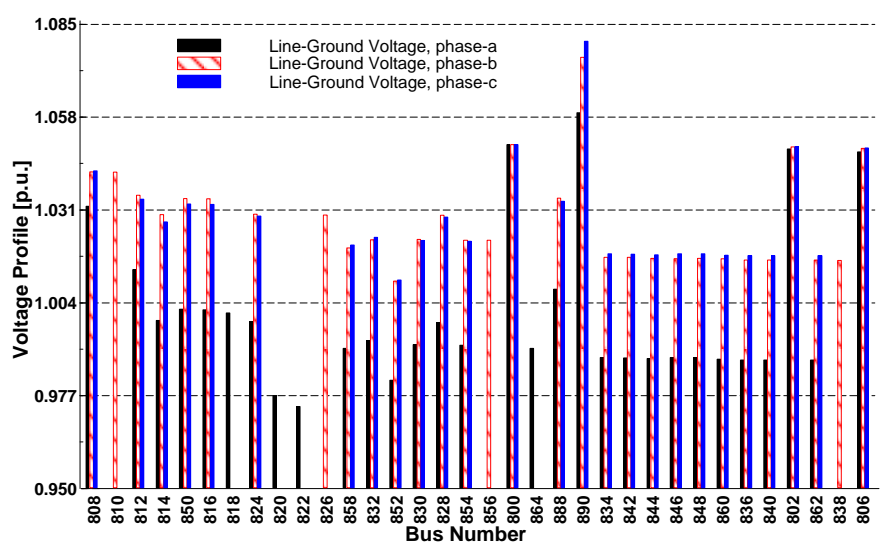

Fig. 5. Voltage profile with $40 \%$ DG penetration at bus 890 .

With 30\% DG penetration at bus 890, all the bus voltage profiles are in the range of 0.95-1.05 p.u. as shown in Fig. 6. Notice that the voltage profile of phase c at bus 890 is 1.0499 p.u., which is very close to the upper voltage limit of 1.05 p.u. Any increase in the DG penetration level at this bus beyond 
$30 \%$ will cause an overvoltage condition at bus 890 . Therefore, considering voltage limits, the maximum penetration of DG units that can be installed at bus 890 is about 30\% (600 kW, $666.66 \mathrm{kVA})$. Furthermore, the total active power loss is reduced to $60.13 \%$ and the maximum loading factor is increased from 2.518 to 3.150 . These results indicate that voltage limits should be considered as a constraint for the methods of DG placement.

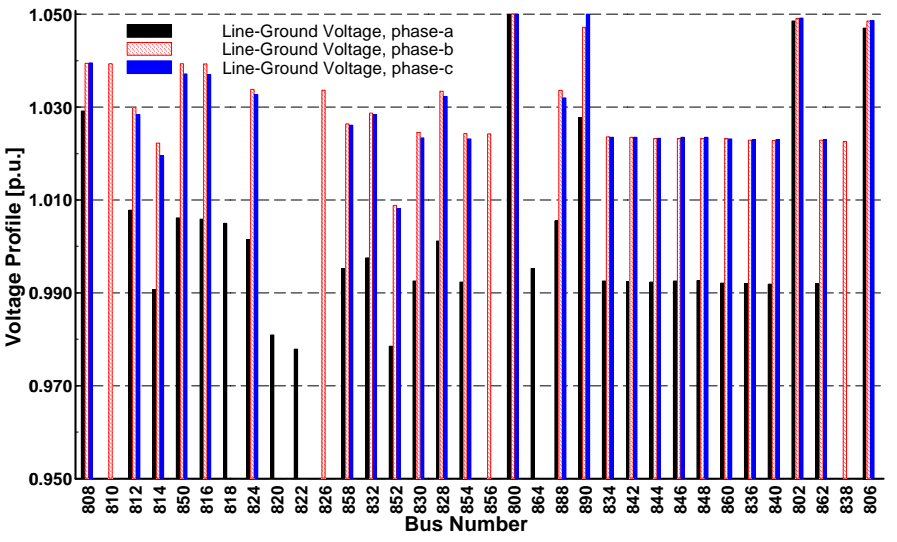

Fig. 6. Voltage profile with 30\% DG penetration at bus 890 .

\section{CONCLUSION}

This paper has extended the application of the conventional bus voltage ranking index of $\mathrm{V} / \mathrm{V}_{\mathrm{o}}$ defined for balanced threephase systems to identify the weakest buses for the placement of DG units in multi-phase systems. Furthermore voltage profiles, active power loss, maximum loading factor, and bus voltage limit have also been investigated. Main conclusions are:

- The proposed bus raking approach based on the positive sequence voltage ratio $\mathrm{V}_{\text {collapse }} / \mathrm{V}_{\text {no-load }}$ can be utilized to locate DG units at the weakest three-phase and single-phase buses.

- Analysis of simulation results indicates that the penetration level of DG is limited by considering voltage limit rather than grid loss calculation and the maximum loading factor.

- $\quad$ For considering high penetration levels of DG units, it is necessary to take voltage limits in to account.

\section{REFERENCES}

[1] J.H.R. Enslin, "Interconnection of distributed power to the distribution network," IEEE PES Power Systems Conference and Exposition, vol.2, 2004, pp. 726- 731.

[2] L. Ramesh, S.P. Chowdhury, S. Chowdhury, Y.H. Song, and A.A. Natarajan, "Voltage stability analysis and real power loss reduction in distributed distribution system," IEEE/PES Transmission and Distribution Conference and Exposition, 2008, pp.1-6.

[3] M. Hasani and M. Parniani, "Method of Combined Static and Dynamic Analysis of Voltage Collapse in Voltage Stability Assessment," IEEE/PES Transmission and Distribution Conference and Exhibition: Asia and Pacific, 2005, pp.1-6.

[4] R.M. Henriques, N. Martins, J.C.R. Ferraz. H.J.C.P. Pinto, A.C. B. Martins, and S. Carneiro Jr., " Impact of Induction Motors Loads into Voltage Stability Margins of Large Systems," in Proc. PSCC, Seville, Spain, 2002.
[5] H. M. Ayres, W. Freitas, M. C. De Almeida, and L. C. P. Da Silva, "Method for determining the maximum allowable penetration level of distributed generation without steady-state voltage violations," IET Generation, Transmission \& Distribution, , vol. 4, pp. 495-508.

[6] D. Baohua, S. Asgarpoor, and Q. Wei, "Voltage analysis of distribution systems with DFIG wind turbines," in Proc. IEEE Power Electronics and Machines in Wind Applications, 2009. PEMWA 2009., 2009, pp. 1-5.

[7] H. Hedayati, S. A. Nabaviniaki, and A. Akbarimajd, "A Method for Placement of DG Units in Distribution Networks," IEEE Transactions on Power Delivery, vol. 23, pp. 1620-1628, 2008.

[8] K. V. Kumar and M. P. Selvan, "Planning and operation of Distributed Generations in distribution systems for improved voltage profile," in Proc. Power Systems Conference and Exposition, 2009. PSCE '09. IEEE/PES, 2009, pp. 1-7.

[9] M. Alonso and H. Amaris, "Voltage stability in distribution networks with DG," in Proc. IEEE Bucharest PowerTech, 2009, pp. 1-6.

[10] F. M. Nuroglu and A. B. Arsoy, "Voltage profile and short circuit analysis in distribution systems with DG," in Proc. IEEE Canada Electric Power Conference, 2008, pp. 1-5.

[11] G. W. Jones and B. H. Chowdhury, "Distribution system operation and planning in the presence of distributed generation technology," in Proc. IEEE/PES Transmission and Distribution Conference and Exposition, 2008, pp. 1-8.

[12] H. Mori and K. Seki, "Non-linear-predictor-based continuation power flow for unbalanced distribution systems," in Proc. Transmission \& Distribution Conference \& Exposition: Asia and Pacific, 2009, pp. 1-4.

[13] X. P. Zhang, P. Ju, and E. Handschin, "Continuation three-phase power flow: A tool for voltage stability analysis of unbalanced three-phase power systems," IEEE Transactions on Power Systems, vol. 20, pp. 1320-1329. 2005.

[14] P. Juanuwattanakul and M.A.S. Masoum, "Voltage stability enhancement for unbalanced multiphase distribution networks," IEEE Power and Energy Society General Meeting, 2011, pp.1-6.

[15] D. Baohua, S. Asgarpoor, and Q. Wei, "Voltage analysis of distribution systems with DFIG wind turbines," in Proc. IEEE Power Electronics and Machines in Wind Applications, 2009, pp. 1-5.

[16] H. Hedayati, S. A. Nabaviniaki, and A. Akbarimajd, "A Method for Placement of DG Units in Distribution Networks," IEEE Transactions on Power Delivery, vol. 23, pp. 1620-1628, 2008.

[17] G. W. Jones and B. H. Chowdhury, "Distribution system operation and planning in the presence of distributed generation technology," in Proc. IEEE/PES Transmission and Distribution Conference and Exposition, 2008, pp. 1-8.

[18] "Radial Test Feeders," IEEE Distribution System Analysis Subcommittee.

[19] "DIgSILENT PowerFactory Manual," 14.0 ed, 2009.

\section{BIOGRAPHIES}

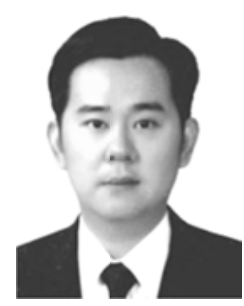

Parachai Juanuwattanakul (S'10) received his B.Eng ( $2^{\text {nd }}$ Class Hons.) and M.Eng degrees in Electrical Engineering from Mahanakorn University of Technology, Bangkok, Thailand and Kasetsart University, Bangkok, Thailand in 1994 and 1998, respectively. He is presently working towards his $\mathrm{PhD}$ degree at the Electrical and Computer Engineering Department, Curtin University of Technology, Perth, Australia. His research interests include voltage stability, distributed generation and FACTS devices. 


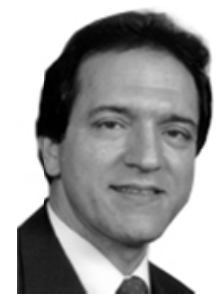

Mohammad A.S. Masoum (S'88-M'91SM'05) received his B.S., M.S. and Ph.D. degrees in Electrical and Computer Engineering in 1983, 1985, and 1991, respectively, from the University of Colorado, Boulder, USA. His research interests include optimization, power quality and stability of power systems/electric machines and distributed generation. Dr. Masoum is the co-author of "Power Quality in Power Systems and Electrical Machines" (Elsevier, 2008) and "Power Conversion of Renewable Energy Systems” (Springer, 2011). Currently, he is an Associate Professor and the discipline leader for electrical power engineering at the Electrical and Computer Engineering Department, Curtin University, Perth, Australia and a senior member of IEEE.

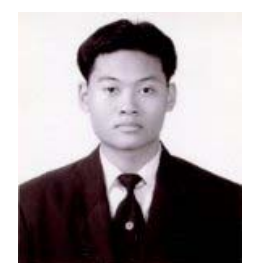

Chittachai Niyomsak (S'11) received his B.Eng degree in Power Electrical Engineering in 2009 from King's Mongkut University of Technology North Bangkok (KMUTNB), Bangkok, Thailand. He is going to graduate his M.Eng degree in 2011 in Renewable Energy Electrical Power Systems, Curtin University, Perth, Australia. His research interests include wind power generation and voltage stability.

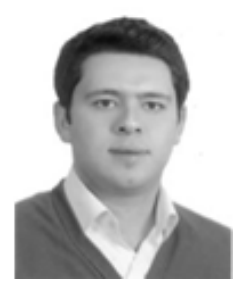

Mansour Mohseni (S'09, M'11) received the B.Sc. and M.Sc. degrees in electrical power engineering from Shahid Chamran University, Ahwaz, Iran, in 2004 and 2007, respectively, and the $\mathrm{PhD}$ degree in electrical and computer engineering from Curtin University, Perth, Australia, in 2011. He is currently an associate lecturer at the Department of Electrical and Computer Engineering, Curtin University, Perth, Australia. He is the author or co-author of over 30 published technical papers in his area of expertise. His research interests include wind power generation, grid integration of renewable energy systems, and power electronics. 